\title{
Learning strategy selection in the water maze and hippocampal CREB phosphorylation differ in two inbred strains of mice
}

\author{
Jin-Young Sung, ${ }^{1}$ June-Seo Goo, ${ }^{1}$ Dong-Eun Lee, ${ }^{2}$ Da-Qing Jin, ${ }^{1}$ Jennifer L. Bizon, ${ }^{3}$ \\ Michela Gallagher, ${ }^{4}$ and Jung-Soo Han ${ }^{1,5,6}$ \\ ${ }^{1}$ Graduate Program in Neuroscience \& Institute for Brain Science and Technology (IBST), Inje University, \\ Daejeon 305-804, South Korea; ${ }^{2}$ Drug Discovery Research Division, Hanwha CC R\&D Center, Daejeon 305-804, South Korea; \\ ${ }^{3}$ Department of Psychology and Faculty of Neuroscience, Texas A\&M University, College Station, Texas 77843, USA; ${ }^{4}$ Department \\ of Psychological and Brain Sciences and Center for Neurogenetics and Behavior, Johns Hopkins University, \\ Baltimore, Maryland 21218, USA
}

\begin{abstract}
Learning strategy selection was assessed in two different inbred strains of mice, C57BL/6 and DBA/2, which are used for developing genetically modified mouse models. Male mice received a training protocol in a water maze using alternating blocks of visible and hidden platform trials, during which mice escaped to a single location. After training, mice were required to choose between the spatial location where the platform had been during training (a place strategy) and a visible platform presented in a new location (a cued/response strategy). Both strains of mice had similar escape performance on the visible and hidden platform trials during training. However, in the strategy preference test, C57BL/6 mice selected a place strategy significantly more often than DBA/2 mice. Because much evidence implicates the hippocampus and striatum as important neural substrates for spatial/place and cued/response learning, respectively, the engagement of the hippocampus was then assessed after either place or cue training by determining levels of CAMP response element-binding protein (CREB) and phosphorylated CREB (PCREB) in these two mouse strains. Results revealed that hippocampal CREB levels in both strains of mice were significantly increased after place in comparison to cued training. However, the relation of hippocampal pCREB levels to training was strain dependent; $\mathrm{pCREB}$ was significantly higher in C57BL/6 mice than in DBA/2 mice after place training, while hippocampal pCREB levels did not differ between strains after cued training. These findings indicate that $p C R E B$, specifically associated with place/spatial training, is closely tied to differences in spatial/place strategy preference between C57BL/6 and DBA/2 mice.
\end{abstract}

Studies with humans and rodents have shown that different neural systems are involved in the ability to learn tasks that depend on information about either place (i.e., spatial/place) and associations between discrete cues and behavioral responses (i.e., cued/response) (McDonald and White 1994; Packard and McGaugh 1996; Hartley et al. 2003). Specifically, spatial/place learning is dependent on the hippocampal system, whereas cued/ response learning is dependent on the striatal system. Further evidence for multiple memory systems comes from studies that have linked specific molecular mechanisms in hippocampus or striatum with the demands of a learning task. One such protein studied extensively in hippocampal-dependent tasks is the cAMP response element-binding protein (CREB), which has been implicated in the formation of long-term memory (Abel and Kandel 1998). Treatments that suppress CREB impair spatial memory (Bourtchuladze et al. 1994; Guzowski and McGaugh 1997). Conversely, treatments that facilitate CREB expression or its function enhance the formation of hippocampal-dependent memory (Josselyn et al. 2001; Chen et al. 2003). Indeed, levels of hippocampal phosphorylated CREB (pCREB) are higher in rats that choose a

\footnotetext{
${ }^{5}$ Present address: Department of Biological Sciences, Konkuk University, Seoul 143-701, South Korea.

${ }^{6}$ Corresponding author.

E-mail jshan06@konkuk.ac.kr; fax 82-2-3436-5432.

Article is online at http://www.learnmem.org/cgi/doi/10.1101/lm.783108.
}

place strategy on a plus maze task than in those that choose a cued/response strategy (Colombo et al. 2003).

Other evidence for multiple memory systems has come from studies of inbred strains of mice that perform differently on learning and memory tasks with different demands. C57BL/6 and DBA/2 strains are two of the background strains commonly used to construct transgenic mouse models with the goal of identifying molecular mechanisms critical for learning and memory function, including the identification of genes that contribute age-related mnemonic disorders, such as Alzheimer's disease. The C57BL/6 and DBA/2 strains can show relatively similar phenotypes in some behavioral assessments (Crawley and Paylor 1997; Brooks et al. 2005). However, other studies report that C57BL/6 and DBA/2 mice can differ in their performance on tasks that are dependent on hippocampal integrity. For example, C57BL/6 mice perform significantly better than $\mathrm{DBA} / 2$ mice on a reference memory version of the water maze task in which mice are trained to escape to a stationary hidden platform (Paylor et al. 1993). Moreover, Passino et al. (2002) reported that C57BL/6 mice strongly preferred a place strategy in a plus maze task whereas no such strategy preference was observed in DBA/2 mice.

Behavioral differences in C57BL/ 6 and $\mathrm{DBA} / 2$ mice coincide with certain neurobiological differences reported in these strains. For example, long-term potentiation (LTP) persists to a greater extent in hippocampus of C57BL/ 6 mice than in DBA/ 2 mice (Matsuyama et al. 1997). Together, these data provide evidence 
that these two inbred strains differ with respect to hippocampaldependent learning and some measures related to hippocampal plasticity. To further examine this relationship, we assessed behavioral strategy preferences of C57BL/6 and DBA/2 male mice in a redundant place/cued version of the water maze task adapted from McDonald and White (1994). In this task, mice received training to a stationary platform across 12 consecutive days with the platform visible on some days and submerged on others. On the final (competition) day, a platform was positioned in the quadrant opposite to where it had been located throughout training and made visible. To assess place/cued strategies, mice were placed in the maze equidistant from the training platform and the newly located visible platform. Mice that visited the training platform location prior to escaping to the visible platform were classified as using a "place strategy," whereas those swimming directly to the new visible (cued) platform were classified as using a "cued strategy." Indeed, in previous studies (McDonald and White 1994; Devan and White 1999), these strategies have been directly linked to hippocampal and dorsal striatal integrity (e.g., animals with hippocampal lesions always choose a "cued strategy" on the competition test consistent with an inability to form a spatial map).

Using additional groups of $\mathrm{C} 57 \mathrm{BL} / 6$ and $\mathrm{DBA} / 2$ mice, a second study then compared levels of hippocampal CREB and pCREB across these strains following sessions of either place or cued training in the water maze to look at differences in the cAMP-signaling pathway. Regulation of cAMP-dependent protein kinase A (PKA) activity via phosphorylation of CREB is a key pathway implicated in neural plasticity and information storage (Silva 2003). Together our data suggest that while DBA/2 mice can accomplish place learning, these mice appear to prefer a nonhippocampal learning strategy and exhibit a corresponding reduction in hippocampal pCREB-dependent signaling.

\section{Results}

\section{Cue-place acquisition in strategy preference task}

Performance during water maze training with alternating blocks of visible and hidden platform trials is shown in Figure 1. Groups of C57BL/6 and DBA/2 mice learned to escape with equal proficiency across both types of trials. For visible platform trials (days $1,2,5,6,9,10$ ), a two-factor ANOVA (strain $\times$ day) indicated that mice improved performance over the course of training $\left(F_{(5,80)}=46.65, P<0.0001\right.$ main effect of day) and that there

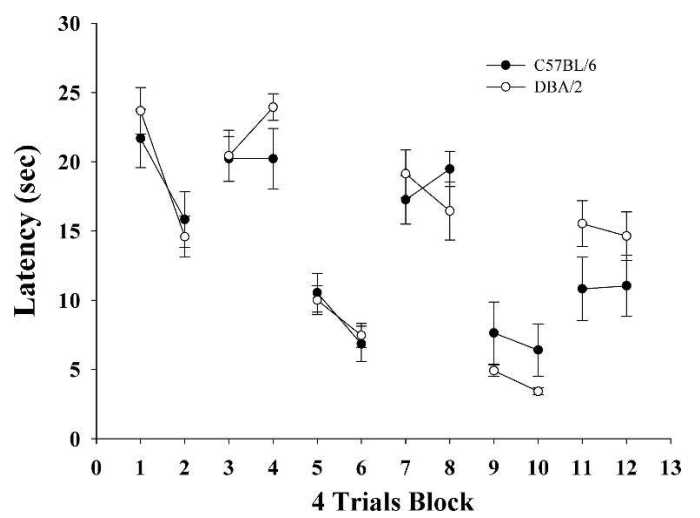

Figure 1. Mean escape latency on each day for C57BL/6 $(n=9)$ and $\mathrm{DBA} / 2(n=9)$ mice. Although the platform was stationary throughout training, it was visible on days $1,2,5,6,9,10$ and hidden on days 3,4 , $7,8,11,12$; there were no reliable differences between $\mathrm{C} 57 \mathrm{BL} / 6$ mice and $\mathrm{DBA} / 2$ mice on either visible or hidden platform training days. See text for statistical analysis.
(A) Place Responders

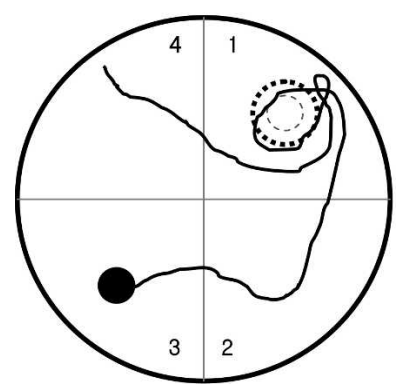

(B) Cued Responders

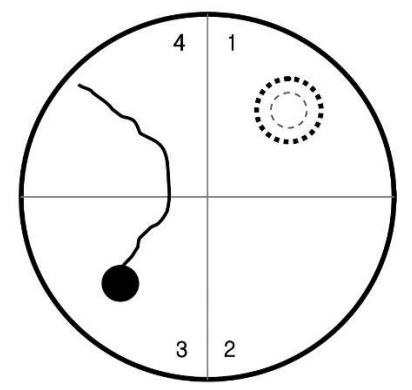

Figure 2. Swim paths from a representative mouse choosing a "place strategy" $(A)$ and a representative mouse using a "cued/response strategy" $(B)$ on the competition test (day 13). Note, in $A$, that the mouse crossed the annulus where the escape platform had been during the previous $12 \mathrm{~d}$ of training, whereas in $B$, the mouse swam directly to the visible platform in its new location.

was no significant main effect of strain $\left(F_{(1,16)}=0.49\right.$, n.s. $)$ or strain $\times$ day interaction $\left(F_{(5,80)}=0.94\right.$, n.s.). Likewise, for hidden platform trials (days $3,4,7,8,11,12$ ), a two-factor ANOVA (strain $\times$ day) indicated that both strains of mice improved over the course of training $\left(F_{(5,80)}=10.15, P<0.001\right)$, with no main effect of strain $\left(F_{(1,16)}=1.68\right.$, n.s. $)$ or interaction between strain and day $\left(F_{(5,80)}=1.50\right.$, n.s. $)$.

\section{Competition test in strategy preference task}

Swim paths during competition testing were analyzed to classify the mice as having used either cued/response or place strategy. Figure 2 shows representative swim paths from mice using each strategy. Mice designated as using a "place strategy" visited the location where the platform had been in the previous training days before escaping to the newly located visible platform. In contrast, mice using a "cued/response strategy" swam directly to the visible platform in its new location. Using the criterion established by McDonald and White (1994), mice were classified as using a place strategy if they visited the previous platform location during either of the two competition tests. All other mice were classified as using a cued/response strategy. As shown in Table 1, eight of nine C57BL/6 mice, but only two of nine DBA/2 mice, used a place strategy. This difference observed between strains on strategy selection was significant using a $\chi 2$ analysis $(\chi 2=8.10, P<0.01)$. As expected, the latency to find the visible platform in the new location on the competition trials was longer for $\mathrm{C} 57 \mathrm{BL} / 6$ mice than $\mathrm{DBA} / 2$ mice, consistent with the C57BL/6 mice taking a more indirect path than DBA/2 mice (Latencies (sec): $\mathrm{C} 57 \mathrm{BL} / 6=9.46 \pm 2.16, \mathrm{DBA} / 2=4.73 \pm 0.48$, $F_{(1,16)}=4.56, P<0.05$; speed $(\mathrm{cm} / \mathrm{sec}):$ C $57 \mathrm{BL} / 6=24.6 \pm 1.7$, $\mathrm{DBA} / 2=23.2 \pm 1.3, F_{(1,16)}=0.43$, n.s. $)$.

\section{CREB and pCREB levels after place/spatial and cued/response training}

In a subsequent experiment, we trained separate groups of mice from both strains on either place or cue learning protocols. For the purpose of the neurobiological assessment that followed, the procedures were implemented across protocols such that training session duration was equated (see Materials and Methods for procedural details). In the spatial learning protocol, mice received 4 training trials per day to a hidden platform for four successive days. Both C57BL/ 6 and DBA/ 2 mice improved over the course of training, as measured by reduced escape latencies $\left(F_{(3,66)}=9.76\right.$, $P<0.001$; Fig. 3). There was no significant main effect of strain $\left(F_{(1,22)}=0.43\right.$, n.s. $)$ nor a significant strain by day interaction 
Table 1. Number of mice that swam to the old location (place responder) versus the new visible platform location (cued responder) on the competition trials

\begin{tabular}{lcc}
\hline & C57BL/6 & DBA/2 \\
\hline "Place responder" old platform location & 8 & 2 \\
"Cued responder" new platform location & 1 & 7 \\
\hline
\end{tabular}

The differences between strains on strategy selection was statistically significant $(\chi 2=8.10, P<0.01)$.

$\left(F_{(3,66)}=0.71\right.$, n.s.; see Fig. 3). Similarly, in separate groups of mice the latency in visible, cued training improved across trials for both C57BL/6 and DBA $/ 2$ mice $\left(F_{(3,66)}=75.17, P<0.001\right.$; Fig. 3) and there was no significant main effect of strain $\left(F_{(1,22)}=0.30\right.$, n.s. $)$ nor a significant strain by day interaction $\left(F_{(3,66)}=0.11\right.$, n.s.; Fig. 3). Mice in these groups were used to evaluate hippocampal CREB and PCREB following sacrifice 30 min after the completion of training.

Figure 4 shows representative immunoblots of hippocampal CREB and PCREB. The relationship between training type and levels of CREB and pCREB was analyzed using two-factor ANOVAs with CREB or pCREB levels as dependent variables. Independent variables were training type (place learning vs. cue learning) and strains (C57BL/6 vs. DBA/2). In both strains, hippocampal CREB levels were significantly increased after place training in comparison with levels observed after cued training. Thus, CREB levels were significantly influenced by training type $\left(F_{(1,44)}=9.69, P<0.01\right.$; Fig. 5), but there was no effect of strain $\left(F_{(1,44)}=0.54\right.$, n.s. $)$ nor a training type $\times$ strain interaction $\left(F_{(1,44)}=0.08\right.$, n.s.). Hippocampal pCREB levels were also significantly influenced by training type $\left(F_{(1,44)}=4.69, P<0.05\right)$ but in a strain-dependent manner. Both a significant effect of strain $\left(F_{(1,44)}=4.384, P<0.05\right)$ and a significant training type $\times$ strain interaction $\left(F_{(1,44)}=4.49, P<0.05\right)$ were evident in the pCREB analysis. Post-hoc comparisons revealed that levels of hippocampal pCREB in C57BL/6 mice after place training were significantly higher than cued training values in that strain, and also in comparisons with place and cued training values in DBA/2 mice $(P<0.05$; Fig. 5B).

\section{Discussion}

In this behavioral comparison of C57BL/ 6 and DBA/ 2 mice, performance during training did not differ between these inbred strains as a function of the task demands. In the traditional water maze task, often used for assessing spatial reference memory, both C57BL/6 and DBA/2 mice performed with similar accuracy (see Fig. 3). Differences in water maze performance have been reported previously for these strains, albeit using somewhat different training protocols (Paylor et al. 1993; Owen et al. 1997; Nguyen et al. 2000b; Brooks et al. 2005; Wahlsten et al. 2005). For example, it was reported that C57BL/6 mice perform better than $\mathrm{DBA} / 2$ mice when spatial reference training with a hidden platform followed cued/response learning with a visible platform (Paylor et al. 1993). Interestingly, others agree with the current findings in reporting no difference between strains when spatial learning was assessed without prior exposure to the maze or cue training (Owen et al. 1997; Brooks et al. 2005).

Against a background of similar performance in the spatial reference memory task, and similar performance during training in the strategy preference task, we found a notable behavioral difference when C57BL/6 and DBA//2 mice were given an option to select a strategy. Specifically, in the protocol that alternated the use of a visible and hidden platform, the mouse strains did not differ in each of those types of training trials. However, only the C57BL/6 mice demonstrated a strong preference for using a place strategy in tests when place and response/cued strategies were put in competition. These data suggest that while the performance of $\mathrm{C} 57 \mathrm{BL} / 6$ and $\mathrm{DBA} / 2$ mice can be indistinguishable during spatial training, these strains differ in their propensity to use a place/spatial strategy.

Our behavioral findings are consistent with strain differences in strategy selection that have been reported in other behavioral assessments, such as a plus-maze task (Passino et al. 2002). Unlike our water maze task, which placed demands on spatial learning in blocks of trials with a hidden platform, both place and response strategies could be equally effective in support of performance throughout training in the plus-maze. In that study, both C57BL/6 and DBA/2 mice were placed in the south arm of the plus-maze and consistently rewarded in the east arm during training. Mice were then tested in probe trials when the start location was in the north arm. In agreement with our results, C57BL/6 mice showed a preferred place strategy in such probe trials by going to the previously rewarded location, that is, the northeast arm. DBA/2 mice, in contrast, did not show this strategy preference but instead demonstrated a greater reliance on a cued/response strategy in these probe trials by making a turn in the same direction (to the right) as they did during training (Passino et al. 2002). In the current investigation, DBA/2 mice similarly lacked the propensity to select the spatial strategy, as exhibited by the C57BL/6 mice, despite the facts that no deficits were evident in the DBA/2 mice when optimal task performance required the use of spatial information during training.

In behavioral settings similar to those used here, brain systems involving hippocampus and dorsal striatum have been shown to mediate place and response strategies, respectively (McDonald and White 1994; Packard and McGaugh 1996; Packard 1999; Packard and Knowlton 2002). Although both neural systems have access to the same information during training experiences, each system appears to be specialized in its information processing functions (Malamut et al. 1984; Packard and Knowlton 2002; White and McDonald 2002). Consistent with that work, Passino et al. (2002) reported that performance in their plus-maze task was associated with increased expression of the immediate early gene and neuronal activity marker c-Fos in both hippocampus and dorsolateral striatum of C57BL/6 mice but only in dorsolateral striatum in the DBA/2 mice (Passino et al. 2002). In a similar experiment using Long-Evans rats, regionally specific pCREB and c-Fos expression in hippocampus and striatum were shown to correlate with place and response strategy selection in individual rats (Colombo et al. 2003).
(A) Place Learning

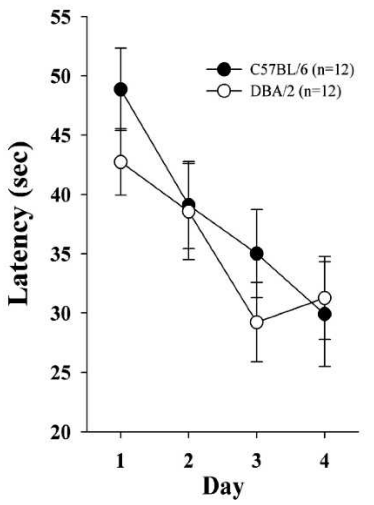

(B) Cued Learning

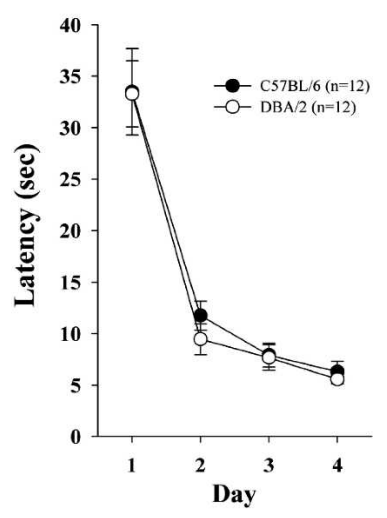

Figure 3. Place $(A)$ and cued $(B)$ training performance of $C 57 \mathrm{BL} / 6$ and $\mathrm{DBA} / 2$ mice. No strain differences were observed on either or cued performance. See text for statistical analysis. 
The cAMP-signaling pathway is one of intracellular signaling pathways involved in learning and memory. The levels of cAMP during learning and memory are affected and modulate the activities of cAMP-dependent PKA. Many studies using electrophysiological techniques and transgenic mice suggest that this kinase/phosphatase is critical for LTP and memory (Silva 2003). For example, transgenic mice that overexpress an inhibitory form of the regulatory subunit for PKA have impaired LTP and memory (Abel and Kandel 1998). Calcium/calmodulin kinase IV (CaMKIV) also activates CREB and, indeed, mice with genetic lesions of CaMKIV show lower pCREB levels after learning compared with wild-type mice (Kang et al. 2001; Wei et al. 2002). Activated CREB (i.e., pCREB) has been suggested to promote gene expression required for learning and memory (Silva 2003).

Therefore, the fact that both $\mathrm{C} 57 \mathrm{~B} / 6$ and $\mathrm{DBA} / 2$ mice have elevated CREB following four days of spatial training in comparisons with cued training suggests that CREB itself can be upregulated following learning at least in multiple training day paradigms as used here. However, the fact that levels of activated (i.e., phosphorylated) CREB were not elevated in the place compared with cue condition in the DBA/ 2 mice strongly suggests that mice of this strain do not use the cAMP signaling pathway widely implicated in hippocampal learning and memory. Together with the data from the strategy task, our data suggest that DBA/2 mice, while able to learn the place of a submerged platform over subsequent days, accomplishes this learning by recruiting differing signaling pathways and/or brain regions than those most often linked to spatial memory formation (i.e., cAMP signaling pathways in hippocampus).

In the present study, hippocampal CREB and pCREB levels in C57BL/6 and DBA/2 mice were assessed 30 min after completion of the final 40-min session in either a place or cued training protocol in the water maze. Hippocampal CREB levels were significantly increased in both C57BL/6 and DBA/2 mice in place compared with cued training conditions. In contrast, hippocampal pCREB levels were significantly elevated in place training compared with cued training in C57BL/ 6 but not in DBA/ 2 mice. These findings indicate that pCREB, a marker associated with plasticity, provides a signature in the hippocampus of C57BL/6 mice that coincides with their bias in selecting a spatial strategy. Other data also distinguish hippocampal structure and function in C57BL/6 mice compared with DBA/2 (Barber et al. 1974). The increased phosphorylation of CREB as a function of spatial/place training reported here may be particularly relevant to strain differences in the neural changes that underlie hippocampaldependent long-term memory. Specifically, the maintenance of the late-phase of LTP, which depends on transcriptional activa-

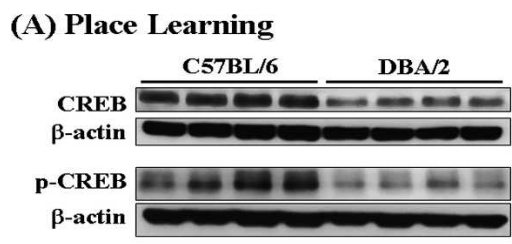

\section{(B) Cued Learning}

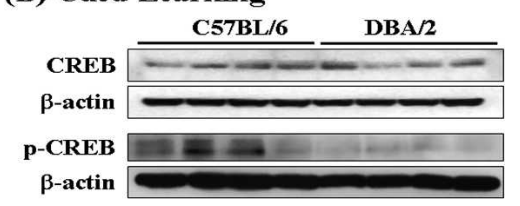

Figure 4. Representative immunoblots of hippocampal $C R E B$ and pCREB from C57BL/6 and DBA/2 mice 30 min after place $(A)$ or cued $(B)$ training.
(A)

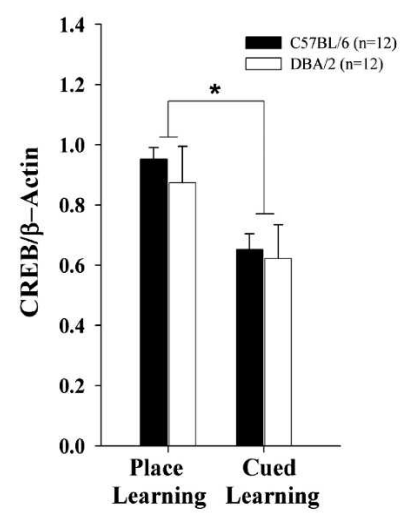

(B)

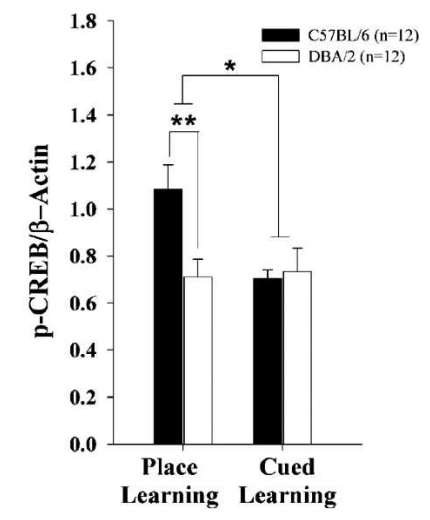

Figure 5. Quantification of hippocampal CREB $(A)$ and pCREB $(B)$ levels (mean \pm S.E.M) from C57BL/6 and DBA/2 mice 30 min after place or cue training. Data are expressed as the ratio of CREB/actin and pCREB/actin. Asterisk $\left(^{*}\right)$ indicates significantly greater hippocampal CREB following place in comparison to cue training in both mouse strains. Double asterisk $\left.{ }^{(*}\right)$ indicates hippocampal pCREB in C57BL/6 mice after place training was significantly greater than all other conditions. See text for statistical analysis.

tion, is robust in C57BL/6 compared with DBA/2 (Nguyen 2006; Nguyen et al. 2000a,b).

To elucidate the roles of genes and intracellular signaling pathways in learning and memory, transgenic and knockout mice are widely used to uncover key molecular mechanisms (Picciotto and Wickman 1998; Wehner et al. 2001). The use of genetically defined inbred strains of mice can also be informative models for such analysis, as indicated by the occurrence of a hippocampal phenotype that differs between the comparison strains in this investigation. Because DBA/2 mice present a behavioral profile together with a deficiency in a major plasticity pathway with the hippocampus, this strain may provide a suitable model for experimental analysis with the goal of enhancing hippocampal dependent learning and memory. In contrast, these data indicate that the C57BL/6 mouse strain may be the superior background strain for genetic analysis of the molecular mechanisms underlying learning and memory in the hippocampal system.

\section{Materials and Methods}

\section{Subjects}

Thirty-three male C57BL/6 and 33 male DBA/2 mice (SPF) obtained from Charles River Co. were $3 \mathrm{mo}$. old at the beginning of the experiments. Mice were housed in groups of four to a cage, in a temperature- and humidity-controlled room, with a 12-h light/ dark cycle (lights on, 07:00-19:00 h). Food and water were available ad libitum. All testing was conducted during the light cycle. Experiments were conducted in compliance with the Inje University's Council Directive for the use and care of laboratory animals.

\section{Apparatus}

The water maze consisted of a circular tank (1.50 m diameter and $0.46 \mathrm{~m}$ height) with an escape platform centered in one of the four maze quadrants. Water $\left(27^{\circ} \mathrm{C}\right)$ was made opaque with nontoxic white paint. The escape platform was located $0.5 \mathrm{~cm}$ beneath the surface on hidden platform training days and raised $2 \mathrm{~cm}$ above the water surface on visible platform training days. The maze was surrounded by white curtains to which were affixed black felt patterns for the purpose of providing distal visual (spatial) cues. Data were recorded with a HVS Image tracking system. 


\section{Behavioral training procedure}

\section{Strategy training}

In a protocol adapted from McDonald and White (1994), C57BL/6 $(n=9)$ and DBA/2 $(n=9)$ mice received four trials per day for 12 successive days, starting each trial from one of four equidistantly located positions at the perimeter of the maze. The location of the platform remained constant across all training trials. On both visible and hidden platform days, the mice were placed into the water facing the wall and allowed $30 \mathrm{sec}$ to escape. The trial ended when the mice climbed on the available platform or after the 30-sec interval had elapsed. If a mouse did not locate the platform during a trial, it was placed on the platform by the experimenter. Mice were left on the platform for 20 sec and then were moved to a holding cage for a 10-min intertrial interval. On days 1 and 2, mice were trained to locate a visible platform in the northeast quadrant of the pool, followed by a third and fourth day on which the platform was submerged (hidden) at the same location. This 4-d sequence was repeated two more times on days 5-8 and 9-12 for a total of 48 trials (24 visible and 24 hidden). On day 13, a competition test was given in which the visible platform was positioned in the southwest quadrant (opposite its placement on training days). Two trials were given with start points equidistant from the two platform locations (NE and SW). Video recordings were analyzed to determine if mice swam within $5 \mathrm{~cm}$ of the previous platform location prior to escaping to the visible platform.

\section{Place and cue training for CREB and pCREB measurements}

\section{Place training}

C57BL/6 $(n=12)$ and DBA/2 $(n=12)$ mice received 4 trials/day (10-min intertrial interval, maximum trial duration of $60 \mathrm{sec}$ with $20 \mathrm{sec}$ on the platform at the end of each trial). All other procedures were identical to those described above.

\section{Cue training}

C57BL/6 $(n=12)$ and DBA/2 $(n=12)$ mice received 4 trials/day (10-min intertrial interval, maximum trial duration of $60 \mathrm{sec}$ with $20 \mathrm{sec}$ on the platform at the end of each trial) in which the visible platform was moved to different locations in the pool between trials. Blank white curtains were drawn around the pool during cue training to occlude extramaze cues.

Thirty minutes after the last training trial on the fourth day in both protocols, all mice were sacrificed. The hippocampi were rapidly dissected and frozen at $-80^{\circ} \mathrm{C}$ until further processing.

\section{Western blot analysis}

Proteins for the analysis of CREB and PCREB were extracted in the following manner. Individual tissue samples were weighed and then homogenized in $5 \mathrm{vol}$ of ice-cold buffer containing $20 \mathrm{mM}$ Tris at pH 7.5, 5\% glycerol, $1.5 \mathrm{mM}$ EDTA, $40 \mathrm{mM} \mathrm{KCl}$, $0.5 \mathrm{mM}$ dithiothreitol, and protease inhibitors (No. 539131, Calbiochem). Homogenates were centrifuged at $20,800 \mathrm{~g}$ for $30 \mathrm{~min}$ at $4^{\circ} \mathrm{C}$. The supernatant was removed from each sample, and an aliquot was taken for determination of total protein concentration using Bradford Reagent. The proteins were then separated by SDS-PAGE and transferred to a PVDF membrane. The membrane was incubated with a primary antibody $(\mathrm{Ab})$ against CREB (1:1000, Cell Signaling) and pCREB, phosphorylated on serine133 (1:1000, Upstate). After primary incubation, blots were incubated with the horseradish peroxidase (HRP)-conjugated secondary $\mathrm{Ab}$ (1:2500, Amersham Biosciences). Blots were visualized using an ECL system and developed using Hyperfilm (Amersham). The relative expression levels of CREB and PCREB were determined by densitometry and normalization to $\beta$-actin (1:5000, Sigma), an invariant cytoskeletal protein.

\section{Data analysis}

Escape latencies during training were analyzed using a repeated measures two-factor ANOVA (strain $\times$ trial block [day]) to evaluate acquisition in the place and cue learning tasks. For analysis of performance in the strategy assessment protocol, path lengths in the training trials were analyzed separately for visible and hidden platform trials (strain $\times$ day ANOVA). On the competition test, mice were given two trials. Each mouse was designated as using a "place strategy" if it swam within $5 \mathrm{~cm}$ of the original platform location on either competition trial. All other mice were classified as using a "cue strategy." A $\chi 2$ analysis was employed to evaluate differences in the frequency of strategies during the competition test. Two-factor ANOVA was conducted with levels of CREB and pCREB as dependent variables. Independent variables were training type (place learning vs. cue learning) and strains (C57BL/6 vs. DBA/2), followed by Bonferroni's post-hoc comparisons. A $P$-value $<0.05$ was considered significant.

\section{Acknowledgments}

This work was supported by Korea Research Foundation Grant funded by Korea Government (MOEHRD, Basic Research Promotion Fund; KRF-2005-003-E00220) to J.-S.H., and NCRR grant 1PO40 RR017688 to M.G. and R01 AG029421 to J.L.B.

\section{References}

Abel, T. and Kandel, E. 1998. Positive and negative regulatory mechanisms that mediate long-term memory storage. Brain Res. Brain Res. Rev. 26: 360-378.

Barber, R.P., Vaughn, J.E., Wimer, R.E., and Wimer, C.C. 1974 Genetically-associated variations in the distribution of dentate granule cell synapses upon the pyramidal cell dendrites in mouse hippocampus. J. Comp. Neurol. 156: 417-434.

Bourtchuladze, R., Frenguelli, B., Blendy, J., Cioffi, D., Schutz, G., and Silva, A.J. 1994. Deficient long-term memory in mice with a targeted mutation of the cAMP-responsive element-binding protein. Cell 79: 59-68.

Brooks, S.P., Pask, T., Jones, L., and Dunnett, S.B. 2005. Behavioural profiles of inbred mouse strains used as transgenic backgrounds. II: Cognitive tests. Genes Brain Behav. 4: 307-317.

Chen, A., Muzzio, I.A., Malleret, G., Bartsch, D., Verbitsky, M., Pavlidis, P., Yonan, A.L., Vronskaya, S., Grody, M.B., Cepeda, I., et al. 2003. Inducible enhancement of memory storage and synaptic plasticity in transgenic mice expressing an inhibitor of ATF4 (CREB-2) and C/EBP proteins. Neuron 39: 655-669.

Colombo, P.J., Brightwell, J.J., and Countryman, R.A. 2003. Cognitive strategy-specific increases in phosphorylated cAMP response element-binding protein and c-Fos in the hippocampus and dorsal striatum. J. Neurosci. 23: 3547-3554.

Crawley, J.N. and Paylor, R. 1997. A proposed test battery and constellations of specific behavioral paradigms to investigate the behavioral phenotypes of transgenic and knockout mice. Horm. Behav. 31: 197-211.

Devan, B.D. and White, N.M. 1999. Parallel information processing in the dorsal striatum: Relation to hippocampal function. J. Neurosci. 19: 2789-2798.

Guzowski, J.F. and McGaugh, J.L. 1997. Antisense oligodeoxynucleotide-mediated disruption of hippocampal cAMP response element binding protein levels impairs consolidation of memory for water maze training. Proc. Natl. Acad. Sci. 94: $2693-2698$.

Hartley, T., Maguire, E.A., Spiers, H.J., and Burgess, N. 2003. The well-worn route and the path less traveled: Distinct neural bases of route following and wayfinding in humans. Neuron 37: 877-888.

Josselyn, S.A., Shi, C., Carlezon Jr., W.A., Neve, R.L., Nestler, E.J., and Davis, M. 2001. Long-term memory is facilitated by cAMP response element-binding protein overexpression in the amygdala. J. Neurosci. 21: 2404-2412.

Kang, H., Sun, L.D., Atkins, C.M., Soderling, T.R., Wilson, M.A., and Tonegawa, S. 2001. An important role of neural activity-dependent CaMKIV signaling in the consolidation of long-term memory. Cell 106: $771-783$

Malamut, B.L., Saunders, R.C., and Mishkin, M. 1984. Monkeys with combined amygdalo-hippocampal lesions succeed in object discrimination learning despite 24-hour intertrial intervals. Behav. Neurosci. 98: 759-769.

Matsuyama, S., Namgung, U., and Routtenberg, A. 1997. Long-term potentiation persistence greater in $\mathrm{C} 57 \mathrm{BL} / 6$ than $\mathrm{DBA} / 2$ mice: 
Predicted on basis of protein kinase $C$ levels and learning performance. Brain Res. 763: 127-130.

McDonald, R.J. and White, N.M. 1994. Parallel information processing in the water maze: Evidence for independent memory systems involving dorsal striatum and hippocampus. Behav. Neural Biol. 61: $260-270$.

Nguyen, P.V. 2006. Comparative plasticity of brain synapses in inbred mouse strains. J. Exp. Biol. 209: 2293-2303.

Nguyen, P.V., Duffy, S.N., and Young, J.Z. 2000a. Differential maintenance and frequency-dependent tuning of LTP at

hippocampal synapses of specific strains of inbred mice. J. Neurophysiol. 84: 2484-2493.

Nguyen, P.V., Abel, T., Kandel, E.R., and Bourtchouladze, R. 2000b. Strain-dependent differences in LTP and hippocampus-dependent memory in inbred mice. Learn. Mem. 7: 170-179.

Owen, E.H., Logue, S.F., Rasmussen, D.L., and Wehner, J.M. 1997. Assessment of learning by the Morris water task and fear conditioning in inbred mouse strains and F1 hybrids: Implications of genetic background for single gene mutations and quantitative trait loci analyses. Neuroscience 80: 1087-1099.

Packard, M.G. 1999. Glutamate infused posttraining into the hippocampus or caudate-putamen differentially strengthens place and response learning. Proc. Natl. Acad. Sci. 96: 12881-12886.

Packard, M.G. and McGaugh, J.L. 1996. Inactivation of hippocampus or caudate nucleus with lidocaine differentially affects expression of place and response learning. Neurobiol. Learn. Mem. 65: 65-72.

Packard, M.G. and Knowlton, B.J. 2002. Learning and memory functions of the Basal Ganglia. Annu. Rev. Neurosci. 25: 563-593.
Passino, E., Middei, S., Restivo, L., Bertaina-Anglade, V., and Ammassari-Teule, M. 2002. Genetic approach to variability of memory systems: Analysis of place vs. response learning and fos-related expression in hippocampal and striatal areas of C57BL/6 and DBA/2 mice. Hippocampus 12: 63-75.

Paylor, R., Baskall, L., and Wehner, J.M. 1993. Behavioral dissociations between C57BL/6 and DBA/2 mice on learning and memory tasks: A hippocampal-dysfunction hypothesis. Psychobiology 21: 11-26.

Picciotto, M.R. and Wickman, K. 1998. Using knockout and transgenic mice to study neurophysiology and behavior. Physiol. Rev. 78: $1131-1163$.

Silva, A.J. 2003. Molecular and cellular cognitive studies of the role of synaptic plasticity in memory. J. Neurobiol. 54: 224-237.

Wahlsten, D., Cooper, S.F., and Crabbe, J.C. 2005. Different rankings of inbred mouse strains on the Morris maze and a refined 4-arm water escape task. Behav. Brain Res. 165: 36-51.

Wehner, J.M., Radcliffe, R.A., and Bowers, B.J. 2001. Quantitative genetics and mouse behavior. Аnпu. Rev. Neurosci. 24: 845-867.

Wei, F., Qiu, C.S., Liauw, J., Robinson, D.A., Ho, N., Chatila, T., and Zhuo, M. 2002. Calcium calmodulin-dependent protein kinase IV is required for fear memory. Nat. Neurosci. 5: 573-579.

White, N.M. and McDonald, R.J. 2002. Multiple parallel memory systems in the brain of the rat. Neurobiol. Learn. Mem. 77: 125-184.

Received September 21, 2007; accepted in revised form January 24, 2008. 


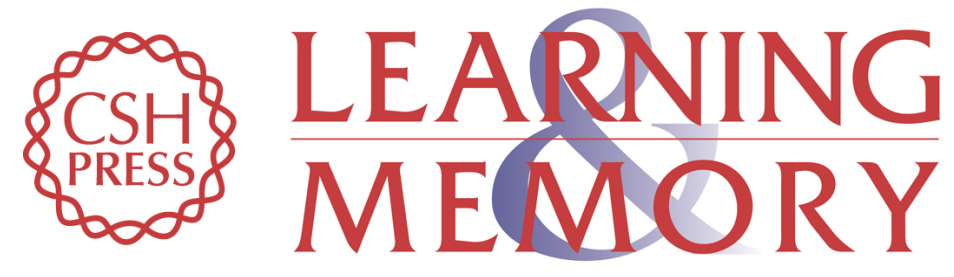

\section{Learning strategy selection in the water maze and hippocampal CREB phosphorylation differ in two inbred strains of mice}

Jin-Young Sung, June-Seo Goo, Dong-Eun Lee, et al.

Learn. Mem. 2008, 15:

Access the most recent version at doi:10.1101//m.783108

References This article cites 30 articles, 7 of which can be accessed free at:

http://learnmem.cshlp.org/content/15/4/183.full.html\#ref-list-1

License

Email Alerting Receive free email alerts when new articles cite this article - sign up in the box at the Service top right corner of the article or click here. 